\title{
Minimal invasive surgery for multiple adhesive small bowel obstruction: Results of a comparative multicenter study
}

\author{
Manejo mínimamente invasivo para las obstrucciones debidas a múltiples adherencias \\ del intestino delgado (OMAID): Resultados de un estudio comparativo múlticentrico
}

\author{
Daniel Gómez ${ }^{1,2}$, Luis F. Cabrera ${ }^{2,4}$, Mauricio Pedraza ${ }^{2,4}$, Andres Mendoza ${ }^{2,4}$, Jean Pulido ${ }^{2,4,6 *}$, \\ Ricardo Villarrea2,3,4, Andres Urrutia ${ }^{2,5}$, Sebastian Sanchez-Ussa ${ }^{2,4}$, and Salomone Di Saverio ${ }^{7}$ \\ ${ }^{1}$ Department of Advanced Laparoscopic Surgery, Centro Policlínico Olaya, Bogotá, Colombia; ${ }^{2}$ Department of General Surgery, Cobos Medical \\ Center, Bogotá, Colombia; ${ }^{3}$ Department of Gastroenterology and Endoscopy, Cobos Medical Center, Bogotá, Colombia; ${ }^{4}$ Department of Medicine, \\ Universidad El Bosque, Bogotá, Colombia; 5 Universidad Pedagógica y Tecnológica de Colombia, Tunja, Colombia; ${ }^{6}$ Surgery Department, Universidad \\ El Bosque, Bogotá, Colombia; ${ }^{7}$ Emergency and Trauma Surgery Unit, Maggiore Hospital Regional Emergency Surgery and Trauma Center-Bologna \\ Local Health District, Bologna, Italy
}

\begin{abstract}
Aim of the study: Laparoscopic adhesiolysis in small bowel obstruction (SBO) is getting increasingly normal. In patients with multiple adhesive SBOs (MASBO), laparoscopic approaches might increase the risk of bowel injury due to the distended and potentially compromised small bowel. It remains a challenge to the surgeons, entails an interdisciplinary team, trying to achieve the least complications as possible. The study aimed to compare surgical outcomes of laparoscopic procedures (multi-port vs. single-port) in the management of MASBO. Patients and Methods: Comparative study of 68 patients with post-operative MASBO treated with Single-Port single incision laparoscopic surgery (SILS) and Multi-port Laparoscopic Surgery in two centers of Bogota, Colombia between January 2013 and June 2018. Results: All patients underwent laparoscopic management, 27 patients by SILS, and 41 patients by multi-port. The average surgical time in the multiport approach was 167 min versus SILS with $129 \mathrm{~min}$. Laparoscopic intestinal resection was performed in 4.4\% of patients, through multi-port using intracorporeal anastomosis. Mean hospital stay of 3.2 days for the SILS approach versus multi-port in 2.2 days. Conclusions: Both laparoscopic approaches, in MASBO treatment is feasible in qualified hands. Patient selection and medical judgment seem to be the most essential factors for a positive result.
\end{abstract}

Key words: Hand-assisted laparoscopy. Intestinal obstruction. Laparoscopy. Surgery. Tissue adhesions.

\section{Resumen}

Objetivos del estudio: Cada día es más frecuente la adherensiolisis laparoscópica en obstrucción del intestino delgado. En pacientes con obstrucciones debidas a múltiples adherencias del intestino delgado (OMAID), los abordajes laparoscópicos pueden incrementar el riesgo de daño de víscera hueca debido a la presencia de asas distendidas. Continúa siendo un reto para el cirujano, requiriendo un grupo interdisciplinario para disminuir las posibles complicaciones. Este estudio busca comparar los desenlaces de abordajes laparoscópicos (Multipuerto vs. monopuerto) en el manejo del OMAID. Pacientes y métodos: Se realizó un estudio de 68 pacientes con OMAID postoperatorio tratado con cirugía laparoscópica de monopuerto y múltipuerto en dos centros de Bogotá, Colombia entre enero de 2013 y junio de 2018. Resultados: Pacientes llevados a manejo laparoscópico, 27 por monopuerto y 41 por múltipuerto, con tiempo quirúrgico promedio de 129 y 167 minutos respectivamente. $4.1 \%$ de los pacientes requirieron resección intestinal, todas en pacientes con abordaje múlti-

Correspondence:

*Jean Pulido-Segura Date of reception: 12-08-2020

C.P. 110141 Bogotá, Colombia Date of acceptance: 06-01-2021

Cir Cir. 2021;89(6):710-717

E-mail: japs1493@gmail.com

DOI: $10.24875 / C I R U .20000895$

Contents available at PubMed

www.cirugiaycirujanos.com

0009-7411/@ 2021 Academia Mexicana de Cirugía. Published by Permanyer. This is an open access article under the terms of the CC BY-NC-ND license (http://creativecommons.org/licenses/by-nc-nd/4.0/). 
puerto con anastomosis intracorpóreas. El tiempo medio de hospitalización fue de 3.2 días para monopuerto y 2.2 días para multipuerto. Conclusiones: Ambos abordajes laparoscópicos son factibles para el manejo del OMAID en manos calificadas. La selección del paciente y el juicio médico parecen ser factores fundamentales en el resultado positivo.

Palabras clave: Laparoscopia. Obstrucción intestinal. Adhesión de tejidos. Cirugía. Laparoscopia asistida

\section{Introduction}

Adhesive small bowel obstruction (ASBO) is one of the leading causes of surgical emergencies in the world. Its surgical approach has been debated because of its implications in morbidity and mortality ${ }^{1}$.

Laparotomy has been the standard treatment for multiple ASBOs (MASBO) referring to adhesive content that occupies more than three abdominal quadrants, finding that epitomizes one of the most difficult and devastating pathologies in the management of small bowel obstruction (SBO), unfortunately, laparotomy still has negative effects in patients. In lasts years, laparoscopic approaches have demonstrated several benefits in the management of $\mathrm{ASBO}^{1-6}$.

In the present study, we compared the single incision laparoscopic surgery (SILS) and the multiport laparoscopic approach for the treatment of MASBO $^{4-6}$.

\section{Materials and methods}

\section{Design}

We conducted a descriptive, retrospective comparative study of patients who underwent adhesiolysis with post-operative MASBO in two centers in Bogota, Colombia between January 2013 and June 2018. In one center, all the patients were managed by SILS due to the availability of the Alexis- $O \circledast$ wound protector, and by decision of the surgeon taking to account their skills and expertise. In the other center, all patients were managed with a multi-port approach performed by two general surgeons.

MASBO diagnosis was based on clinical and radiological findings. All patients underwent abdominopelvic contrast computed tomography previous to the intervention for evaluation of the type, location, and severity of MASBO. A large decompression tube was inserted nasally at least $48 \mathrm{~h}$ to ensure proper bowel decompression. All patients were followed up for at least 12 months after treatment.

Data from 27 patients with MASBO who underwent SILS approach were compared with 41 patients of conventional multiport laparoscopic approach matched for age, gender, and surgical procedure. The sociodemographic and clinical variables that were evaluated can be seen in Table 1. Surgical outcomes are presented in Table 2. All patients above the age of 18 years who underwent the above procedures were included for analysis.

We exclude patients with generalized or localized peritonitis, or free air needing immediate surgery; hemodynamic instability; acute or chronic malnutrition; noncontrolled intra-abdominal or systemic infections; comorbidities that contraindicate laparoscopic approach; previous laparoscopic adhesiolysis and SBO with a single band because of the risk of closed-loop obstruction and strangulation.

Patient consent for laparoscopic surgery and research was obtained before the procedure was started. The protocol was implemented in accordance with the provisions of the Declaration of Helsinki and Good Clinical Practice guidelines and approved by the ethics committee of both hospitals. The authors include four surgeons who operated consecutively during the study period.

\section{Surgical technique}

\section{Patient preparation}

Patients are prepared for laparoscopic management of MASBO with adhesiolysis just as they would be for an open operation. First, in the emergency room, we proceed to the correction of electrolyte levels, fluid resuscitation, and a Foley catheter is placed for an exact urine quantification. A nasogastric tube is also placed for gastric decompression, always making sure that the position and function are optimal. Patients and their families are informed risk of bowel injury, need for additional trocars, and need to conversion and mortality.

\section{EQUIPMENT AND ROOM SET-UP}

Under general anesthesia, patients were placed in the supine position with both arms tucked along their sides 

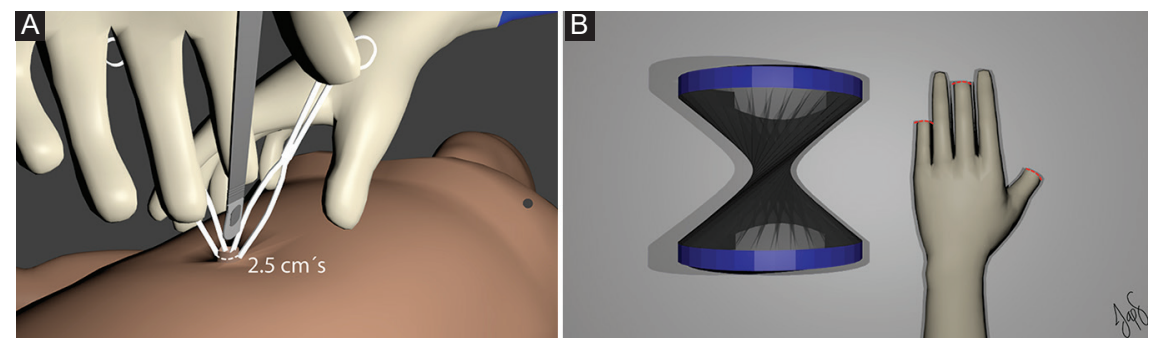

Figure 1. A: Hason's technique. B: 3D model; Wound protector retractor and glove.

and pneumatic stocking. The patient is securely strapped to the surgical bed to facilitate maximum tilting and lateral rotation of the operating table. The surgeon and the first assistant stand on opposite sides of the table. The surgical team should move around the patient according to the operative findings. Then, the surgeon stood in the traditional left cholecystectomy position. The first surgical assistant stood at the right of the surgeon and the scrub nurse to the right of the first assistant.

\section{Single port technique}

In our facility, the single port surgery (SPS) method is routinely used for appendectomy or cholecystectomy, even in challenging cases such as an accessory spleen torsion. It is usually performed by a general surgeon trained on advanced laparoscopy. The procedure of SPS start with a $2.5 \mathrm{~cm}$ skin incision with an open Hasson's technique in the Palmer point or in an area without former surgical incisions (Fig. 1), proper abdominal access has been obtained and the double ring wound protector (Alexis- $\mathrm{Q} \otimes$ wound protector, size small or extra small, from Applied Medical, CA, USA) is positioned and tightened within the incision. Two surgical gloves (size 7.5 , a powder-free surgical glove made of natural rubber latex) are slid down onto the external ring (Fig. 2) and small cuts are then made at the tip of the fingers of the glove in order to get the access for the trocars (Fig. 3) and create the Surgical-Glove Port-like Di Saverio et al. ${ }^{6}$ Pneumoperitoneum was applied using a $12 \mathrm{~mm}$ port with a $12-14 \mathrm{mmHg}$ intra-abdominal pressure.

\section{Multiport technique}

The first surgical assistant stood to the surgeon's right and, the second assistant to the left. The scrub nurse stood to the right of the first surgical assistant. Pneumoperitoneum was created using an open Hasson umbilical approach, introducing a port of $12 \mathrm{~mm}$
Table 1. Baseline demographics and clinical data $(n=68)$. Demographic data of laparoscopic treatment

\begin{tabular}{|c|c|c|c|}
\hline & & $\begin{array}{l}\text { Multiport } \\
(n=41)\end{array}$ & SILS $(n=27)$ \\
\hline Age - mean (range) & $47.4(17-91)$ & $49(17-91)$ & $45(22-90)$ \\
\hline \multicolumn{4}{|l|}{ Sex } \\
\hline F & $42.7 \%$ & $43 \%$ & $42.4 \%$ \\
\hline M & $57.3 \%$ & $56.5 \%$ & $58.1 \%$ \\
\hline BMI - mean (range) & $\begin{array}{c}26.2 \\
(18.7-34.2)\end{array}$ & $\begin{array}{c}26 \\
(18.7-34.2)\end{array}$ & $\begin{array}{c}26.4 \\
(18.7-34.2)\end{array}$ \\
\hline \multicolumn{4}{|l|}{ ASA Class } \\
\hline $1-2$ & $58.3 \%$ & $59 \%$ & $57.6 \%$ \\
\hline 3 & $39.3 \%$ & $39 \%$ & $39.6 \%$ \\
\hline 4 & $2.4 \%$ & $2 \%$ & $2.8 \%$ \\
\hline $\begin{array}{l}\text { Previous abdominal } \\
\text { surgeries (\%) }\end{array}$ & 100 & & \\
\hline $\begin{array}{l}\text { Open appendicectomy } \\
\text { (complicated acute } \\
\text { appendicitis) }\end{array}$ & 13 & 13 & 13 \\
\hline Open cholecystectomy & 5 & 4 & 6 \\
\hline $\begin{array}{l}\text { Exploratory laparotomy } \\
\text { due to trauma }\end{array}$ & 42 & 44 & 40 \\
\hline Gynecologic & 19 & 20 & 28 \\
\hline $\begin{array}{l}\text { Sigmoidectomy due to } \\
\text { diverticulitis (Hinchey } \\
\text { III-IV) }\end{array}$ & 16 & 15 & 17 \\
\hline Others & 5 & 4 & 5 \\
\hline $\begin{array}{l}\text { \# of previous surgeries } \\
\text { mean }\end{array}$ & 2.1 & 2.3 & 2.4 \\
\hline Previous obstruction & $29.5 \%$ & $30 \%$ & $29 \%$ \\
\hline Days to surgery (mean) & 2.3 & 2.5 & 2.1 \\
\hline
\end{tabular}

maintaining an intra-abdominal pressure of $14 \mathrm{~mm} \mathrm{Hg}$. Under direct laparoscopic vision using a 30-degree lens, 4 additional ports were placed; two $12 \mathrm{~mm}$ ports one in the right flank and the other in the left paramedial zone, another two $5 \mathrm{~mm}$ ports were placed, 

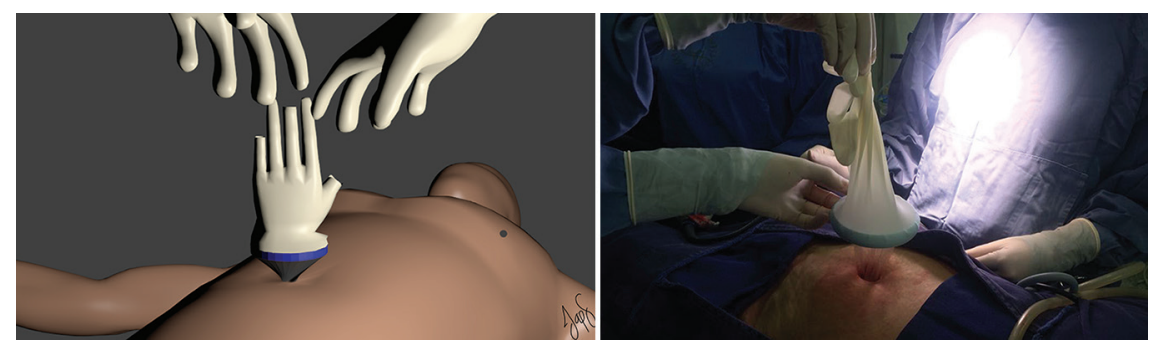

Figure 2. Wound protector and glove placed for single port approach.
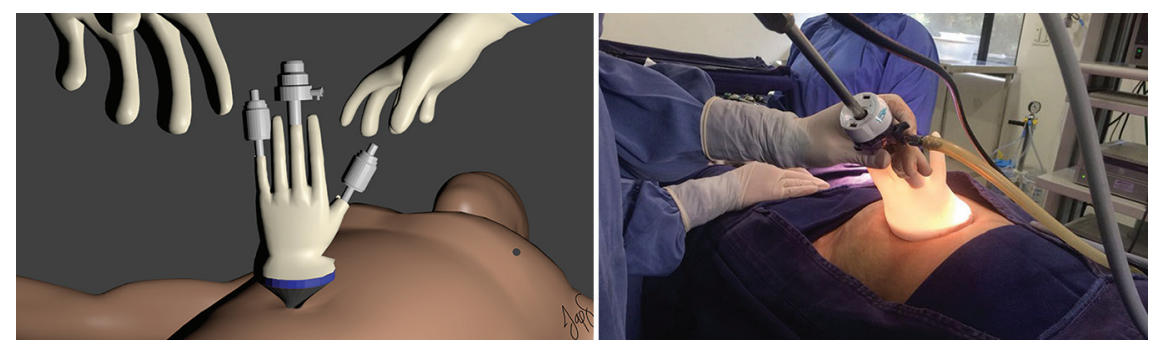

Figure 3. Trocar configuration.
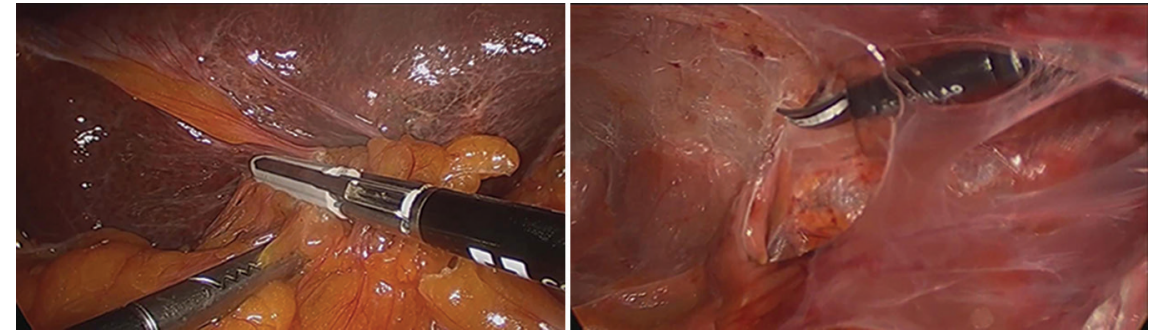

Figure 4. Laparoscopic multiple adhesive small bowel obstruction adhesiolysis.

one in the right subcostal area and the other in the epigastric zone. Using a harmonic cutter (Ethicon Endo Surgery Inc., Cincinnati, OH, USA), adhesion liberation was performed.

\section{Technique for adhesiolysis}

Laparoscopic adhesiolysis was made with laparoscopic scissors, blunt dissector, hydro-dissection, atraumatic graspers, hook, and bipolar forceps, releasing adhesions either by blunt or sharp dissection (Fig. 4). The small bowel was examined from distal to proximal, starting from the ileocaecal valve and when the operator decided that it was impossible to complete the releasing of the ASBO, one or two $5 \mathrm{~mm}$ trocar was added under direct visualization for improve the triangulation. No conversion to open laparotomy was performed if accidental bowel perforation or bowel necrosis was found; all were sutured or resected laparoscopically.

\section{Statistical analysis}

Being an observational retrospective cohort study, a descriptive analysis data were performed. The collected information was analyzed using SPSS1 (Statistical Package for the Social Sciences) 22.0 version calculating: range, median, minimum, maximum, and percentages.

\section{Results}

During the period from January 2013 to June 2018, 278 patients had diagnosed with MASBO, 210 were 
Table 2. Surgical outcomes: laparoscopic multipor versus SILS management of MASBO

\begin{tabular}{lccc}
\hline & Total & $\begin{array}{c}\text { Multiport } \\
(\mathbf{n}=\mathbf{4 1})\end{array}$ & $\begin{array}{c}\text { SILS } \\
(\mathbf{n}=\mathbf{2 7})\end{array}$ \\
\hline Conversion & $1(1.4)$ & 1 & 0 \\
Drains & $11(16.1)$ & 8 & 3 \\
Estimated blood loss (cc) & 15 & 19 & 11 \\
Length of hospital stay & $5.2(3-28)$ & 6,3 & 4,1 \\
(days) & 148,3 & 167,5 & 129,2 \\
Operative time & $3(4.4)$ & 3 & 0 \\
Small bowel resection (cm) & 37.3 & 43,4 & 31,2 \\
Time to flatus (hours) & $(11-127)$ & & \\
& $36.2(9-171)$ & 39,1 & 33,3 \\
\hline Time to oral intake (hours) & & & \\
\hline
\end{tabular}

Table 3. Postoperative complications

\begin{tabular}{lccc}
\hline & Total & Multiport & SILS \\
\hline Surgical site infection & 2 & 2 & 0 \\
Superficial & 0 & 0 & 0 \\
Deep & 2 & 2 & 0 \\
Ileus & 1 & 1 & 0 \\
Re Intervention due to SBO & 0 & 0 & 0 \\
Missed enterotomy that required & 0 & 0 & 0 \\
reoperation & & & \\
Readmission & 5 & 3 & 2 \\
Recurrent SBO & $(7.3)$ & & 0 \\
Mortality & 0 & 0 & 0 \\
SBO: Small Bowel Obstruction: LESS: & 0 & 0 & 0 \\
\hline
\end{tabular}

excluded from the study because they were managed with an open approach or didn't require a surgical approach. Sixty-eighth patients with the laparoscopic approach with MASBO were included in the study.

From the total number of patients that underwent laparoscopic MASBO management, 27 patients through SILS and 41 patients through multiport, the mean age of the total population was 47.4 years, $42.7 \%$ female, and $57.3 \%$ male. Mean body mass index of 26.2. ASA's classification Grade II of $58.3 \%$, Grade III $39.3 \%$, and Grade IV 2.4\%, as we can see in Table 1.
One hundred percent of the patients had at least two previous abdominal surgeries with an average number of previous abdominal surgeries of 2.1. A previous ASBO episode in $29.5 \%$ and none previous laparoscopic adhesiolysis. The previous surgical antecedents in both groups are presented in Table 1.

The meantime between medical management to surgery was 2.3 days. The average surgical time in the multiport approach was 167 min, higher than SILS with $129 \mathrm{~min}$. Mean blood loss in both approaches was non-significant. Laparoscopic intestinal resection in $4.4 \%$ of patients due to signs of ischemia or necrosis, all by multiport with intracorporeal anastomosis. Only $16.1 \%$ of patients needed a drain. Meantime to flatus was 37.3 hours for the SILS approach 40.2 versus multiport group that was 43.4 hours. Time to oral intake average of $36.2 \mathrm{~h}$, less for the SILS approach versus multiport in $5.8 \mathrm{~h}$, due to the wait in patients that required resection and anastomosis. Mean hospital stay of 5.2 days, less for the SILS approach versus multiport in 2.2 days. The conversion rate of $1.4 \%$, only in the multiport approach group in one patient with a polypropylene heavyweight mesh incorporated in the small bowel, all summarized in Table 2.

Post-operative complications were two surgical site infections and one post-operative ileus in the group of multiport approach. None missed enterotomy were presented. Two patients had readmission. Surgical reintervention was not necessary, and no deaths were documented in both groups in a follow-up period ranging from 6 months to 5 years, Table 3 .

\section{Discussion}

The risk of SBO is very high, especially after more than one surgical intervention. Between 20 and 30 percent of the patients requiere adhesiolysis surgery to solve SBO. Abdominal exploration through laparotomy has been the standard treatment for SBO, but laparotomies increase the risk of fibrous adhesions in approximately $95 \%$ of patients with a post-operative ASBO risk of $3 \%^{2-5}$.

Laparoscopic adhesiolysis for ASBO has demonstrated several benefits, including smaller incisions, lower intraoperative bleeding, decrease adhesion formation, earlier return of bowel function, less postoperative pain, shorter hospital stay, reduced recovery time, allowing a faster return to full activity, and low rate of surgical site infection and intra-abdominal contamination $^{2-5}$. Also reduce post-operative adhesion creation as reported by Lombardo et al. in a 
population-based propensity score-matched analysis including 6762 patients where laparoscopic treatment for ASBO is not related with a significant difference in operative time, rates of re-intervention within 30 days or mortality ${ }^{7,8}$. Nevertheless, an exhaustive analysis of the studies that showed the superiority of laparoscopy approaches could be related to a strong selection bias allocating mainly the less severe cases to laparoscopy'.

The foremost case report of a laparoscopic adhesiolysis in ASBO was made by Kelly et al. in 1991, since that time, there have been several studies that attest to the success of laparoscopic adhesiolysis as shown by Nagle et al. between 1980 and 20029,10.

For MASBO, laparoscopy has been controversial management because laparoscopic adhesiolysis in a very distended loops of bowel and multiple complex adhesions increase the risk of a bowel injury due to a difficult dissection of this approach ${ }^{1,2}$. Guidelines recommend a careful selection of candidates for laparoscopic treatment ${ }^{1}$.

Laparoscopic patient selection for the single or multiport approach is still a controversial issue; some experts recommend that exclusion criteria are correlated hemodynamic instability or cardiopulmonary impairment, pneumoperitoneum intolerance. The relative contraindication depends on the surgeon's laparoscopic skills, just like in our study. To the best of our knowledge, this is the first comparative retrospective study of minimally invasive techniques for MASBO management, also it is the largest series of SILS management.

There are several factors that we take into account and some authors have been appeared to anticipate an effective result as Nagle et al. and Naegle et al. ${ }^{10}$ The surgeon needs to be trained and capable of performing advanced laparoscopy to achieve good results. Nagle et al. and Chosidow et al..$^{10,11}$ laparoscopic adhesiolysis on an emergent basis in 39 patients; the conversion rate was $36 \%$ compared with $7 \%$ in elective cases; for that reason, we prefer elective cases; however, an algorithm for selecting patients has not been established.

Patients without peritonitis who do not resolve with non-operative management should be considered for laparoscopic adhesiolysis, we take into account bowel diameter, degree of abdominal distention, and location of the obstruction (i.e. proximal or distal), as were recommended by Naege in a review of The American Journal of Surgery ${ }^{10}$. Suter et al. found that a bowel diameter exceeding $4 \mathrm{~cm}$ was associated with an increased rate of conversion: $55 \%$ versus $32 \%$ $(p=0.02)^{12}$. We recommend taking an abdominopelvic computed tomography who provide additional information about the location of the transition point and delineate a complete from a partial obstruction.

Laparoscopic adhesiolysis is technically challenging, given the bowel distension and the possibility of iatrogenic injuries if the small bowel is not properly handled. Independent predictors of bowel injury reported in the literature are previous laparotomies, anatomical site of the intervention, existence of bowel fistula, and laparotomy through a pre-existing median incision, but in our study none missed enterotomy were presented with a lower incidence than those reported in the literature by Di Saverio et al. in 2018 with 83 patients and 4 missed enterotomy with a current rate of iatrogenic full-thickness bowel lesion of $4.8 \% 6-8,13$

The Bologna guidelines recommend open surgery as the first-line therapy; however, disadvantages of a large abdominal incision include growing post-operative pain, prolonged intestinal paresis, surgical site infection, ventral incisional hernia, poor cosmesis, and more adhesions, making more difficult and more dangerous to perform successive operations.

Besides, that laparoscopic surgery generates fewer post-operative adhesions than open surgery, but in the management for ASBO it's a second-line therapy, reserve for the presents of sufficient experience, less than two previous laparotomies and when a single adhesive band is expected. Our study demonstrated that single and multiport laparoscopic adhesiolysis is effective and useful in MASBO with more than two previous laparotomies. The present study showed that surgical outcomes in the single port group, such as time to oral intake, intervention time, blood loss and hospital stay were superior to those in a conventional multiport laparoscopic approach. Similar results are reported in 2016 by Okamoto et al. ${ }^{1}$ for the management of single ASBO, 27 patients taken to Single-Port and multi-port Laparoscopic Surgery with a mean intervention time was $105 \mathrm{~min}$ in the SILS group and $116 \mathrm{~min}$ in the multiport laparoscopic group. Patients restarted oral intake after a mean of 2 days in the SILS and 3 days in the multiport groups and the length of hospital stay was shorter in the SILS group (5 days vs. 7 days) with no statistical difference ${ }^{1,5,14}$. Comparable results with those found, with a longer surgical time in the multiport patient group compared to the SILS group, probably due to the need for small bowel resection. 
Surgeons should not hesitate to convert to multiport procedure and/or the conventional open surgery patients in surgical management for MASBO due to the limitation of retro posterior view or a smaller pelvic cavity. Finarella et al. described predictive factors for no laparoscopic adhesiolysis conversion are a number of previous laparotomies $\leq 2$, non-median preceding laparotomy, appendectomy, single band adhesion, prompt laparoscopic treatment within $24 \mathrm{~h}$ from the onset of symptoms, no signs of peritoneal irritation, and experience of the surgeon. The conversion rate in our study with MASBO and a mean of 2.3 previous laparotomies was only $1.4 \%$ for the laparoscopic multi-port approach and $0 \%$ for the single port approach, results lower than those described by Okamoto et al. ${ }^{1}$ Miller et al. and Borzellino et al. from $6.2 \%$ to $52 \%{ }^{15,16}$. Only Di Saverio et al. reported a conversion rate of $3.5 \%$, but they do not include MASBO patients with diffuse and dense matted adhesions like in our study ${ }^{14-19}$.

Previous studies have shown that patients in whom a laparoscopic procedure was intended had fewer postoperative complications. In our study were not reported early surgical complications for the single port approach group. On the other hand, in the group of the multi-port approach $2.8 \%$ of patients present surgical site infection, explained by the need for bowel resection. Two patients presented readmission due to obstructive intestinal symptoms that they subsequently resolved with medical management, which presented surgical history of sigmoidectomy for acute diverticulitis Hinchey III and IV, at the 1-year follow-up, they did not repeat the SBO episode, so they probably did not require surgical management again. Others operative complications such as post-operative bronchoaspiration, postoperative ileus, missed enterotomy, and pulmonary embolism were less to those in the multiport laparoscopic group ${ }^{1,3,5,17-20}$. The main limitation of this study is that is an observational comparative study without randomization. It is, therefore, subject to selection bias. In addition, as the occurrence of complications is low, the size of our study may be too small to find the incidence of complications in this type of technique. Finally, a laparoscopic single port and multi-port approach for MASBO surgery seem to be as safe as the conventional procedure, further work, including randomized trials, needs to be directed to show equivalence/improved results compare to the open approach.

\section{Conclusions}

For the treatment of MASBO, SILS and Multi-Port laparoscopic surgery are both feasible and safe, being
SILS technically more challenging, requiring experienced hands surgeon and more appropriate patient selection for this surgical approach. Medical judgment appears to be the most important factor for a successful outcome.

\section{Conflicts of interest}

The authors do not declare any conflicts of interest.

\section{Ethical disclosures}

Protection of human and animal subjects. The authors declare that no experiments were performed on humans or animals for this study.

Confidentiality of data. The authors declare that they have followed the protocols of their work center on the publication of patient data.

Right to privacy and informed consent. The authors declare that no patient data appear in this article.

\section{References}

1. Okamoto H, Maruyama S, Wakana H, Kawashima K, Fukasawa T, Fujii $\mathrm{H}$. Feasibility and validation of single-port laparoscopic surgery for simple-adhesive or non adhesive ileus. Medicine (Baltimore). 2016;95:e2605.

2. Hiro J, Inoue $Y$, Okugawa $Y$, Kawamoto A, Okita $Y$, Toiyama $Y$, et al. Single-port laparoscopic management of adhesive small bowel obstruction. Surg Today. 2014;44:586-90.

3. Van Steensel S, Van den Hil LC, Schreinemacher MH, Ten Broek RP, van Goor H, Bouvy ND. Adhesion awareness in 2016: an update of the national survey of surgeons. PLoS One. 2018;13:e0202418.

4. Behman R, Nathens AB, Look Hong N, Pechlivanoglou P, Karanicolas PJ. Evolving management strategies in patients with adhesive small bowel obstruction: a population-based analysis. J Gastrointest Surg. 2018;22:2133-41.

5. Ten Broek RP, Krielen P, Di Saverio S, Coccolini F, Biffl WL, Ansaloni L, et al. Bologna guidelines for diagnosis and management of adhesive small bowel obstruction (ASBO): 2017 update of the evidence-based guidelines from the world society of emergency surgery ASBO working group. World J Emerg Surg. 2018;13:24.

6. Di Saverio S, Birindelli A, Broek RT, Davies JR, Mandrioli M, Sallinen V. Laparoscopic adhesiolysis: not for all patients, not for all surgeons, not in all centres. Updates Surg. 2018;70:557-61.

7. Lombardo S, Baum K, Filho JD, Nirula R. Should adhesive small bowel obstruction be managed laparoscopically? A national surgical quality improvement program propensity score analysis. J Trauma Acute Care Surg. 2014;76:696-703.

8. Byrne J, Saleh F, Ambrosini L, Quereshy F, Jackson TD, Okrainec A. Laparoscopic versus open surgical management of adhesive small bowel obstruction: a comparison of outcomes. Surg Endosc. 2015;29:2525-32.

9. Kelly KN, Iannuzzi JC, Rickles AS, Garimella V, Monson JR, Fleming FJ. Laparotomy for small-bowel obstruction: first choice or last resort for adhesiolysis? A laparoscopic approach for small-bowel obstruction reduces 30-day complications. Surg Endosc. 2014;28:65-73.

10. Nagle A, Ujiki M, Denham W, Murayama K. Laparoscopic adhesiolysis for small bowel obstruction. Am J Surg. 2004;187:464-70.

11. Chosidow D, Johanet $H$, Montario T, Kielt R, Manceau C, Marmuse JP, et al. Laparoscopy for acute small-bowel obstruction secondary to adhesions. J Laparoendosc Adv Surg Tech. 2000;10:155-9.

12. Suter M, Zermatten P, Hakic N, Martinet O, Bettschart V. Laparoscopic management of mechanical small bowel obstruction: are there predictors of success or failure? Surg Endosc. 2000;14:478-84.

13. Vettoretto N, Carrara A, Corradi A, De Vivo G, Lazzaro L, Ricciardelli L, et al, Italian Association of Hospital Surgeons (Associazione dei Chirurghi Ospedalieri Italiani-ACOI). Laparoscopic adhesiolysis: consensus conference guidelines. Colorectal Dis. 2012;14:e208-15. 
14. Catena F, Di Saverio S, Coccolini F, Ansaloni L, De Simone B, Sartelli M, et al. Adhesive small bowel adhesions obstruction: evolutions in diagnosis, management and prevention. World J Gastrointest Surg. 2016;8: 222-31.

15. Miller G, Boman J, Shrier I, Gordon PH. Natural history of patients with adhesive small bowel obstruction. Br J Surg. 2000;87:12407.

16. Borzellino G, Tasselli S, Zerman G, Pedrazzani C, Manzoni G. Laparoscopic approach to postoperative adhesive obstruction. Surg Endosc. 2004;18:686-90.
17. Behman R, Nathens AB, Byrne JP, Mason S, Look Hong N, Karanicolas $\mathrm{PJ}$. Laparoscopic surgery for adhesive small bowel obstruction is associated with a higher risk of bowel injury: a population-based analysis of 8584 patients. Ann Surg. 2017;266:489-98.

18. Ward BC, Panitch A. Abdominal adhesions: current and novel therapies. J Surg Res. 2011;165:91-111.

19. Salama T. Laparoscopic management of acute intestinal obstruction. Surg Curr Res. 2017;7:2

20. Choi BJ, Kim SJ, Lee SC, Lee Jl. Single-port laparoscopic treatment of small bowel obstruction. Am J Surg. 2014;208:470-5. 